\title{
Valoração dos Serviços Ecossistêmicos Culturais: mensuração econômica do Bumba Meu Boi do Maranhão
}

\section{Valuation of Cultural Ecosystem Services: economic measurement of Bumba meu Boi do Maranhão (Brazil)}

\author{
Sérgio Roberto Pinto, Abigail Cardoso Coqueiro, Rodrigo Burkowski, \\ Fabrício Brito Silva
}

\begin{abstract}
RESUMO: O Bumba meu Boi do Maranhão é uma tradicional manifestação cultural brasileira. Nos últimos anos, houve crescente interesse por valorar a variável cultural entre os serviços ecossistêmicos. Constitui-se um desafio valorar uma tradição que reúne elementos constitutivos que configuram uma linguagem estética, expressada pelos corpos humanos que a cultivam, reconhecida como riqueza do patrimônio cultural e imaterial pelo Instituto do Patrimônio Histórico e Artístico Nacional. Esta pesquisa tem como objetivo compreender o serviço ecossistêmico cultural e expressar, monetariamente, esse valor; utilizou, para tanto, o Método de Valoração Contingente. Observou-se que essa manifestação possui um valor econômico cuja Disposição a Pagar, por indivíduo participante da pesquisa, foi de $R \$ 34.24$, e isso ocasiona uma totalidade de $R \$ 10.272 .000,00$ (dez milhões, duzentos e setenta e dois mil reais) baseado no universo total do público presente no São João na Ilha de São Luís - MA. Os resultados indicam que o bumba meu boi do Maranhão, por ser considerado uma manifestação Cultural, possui valor econômico atribuído à sua imponência cultural.
\end{abstract}

PALAVRAS CHAVE: Valoração das Manifestações Culturais; Bumba meu Boi; Festejo de São João; Disposição a Pagar.

ABSTRACT: Bumba meu Boi of Maranhao is a traditional Brazilian cultural event. In recent years there has been an increasing interest in valuing the cultural variable among ecosystem services. It is a challenge to value a tradition that brings together constitutive elements that configure an aesthetic language expressed by the human bodies that cultivate them, recognized as a wealth of cultural and immaterial heritage by the National Historical and Artistic Heritage Institute. This research aims to understand ecosystemic cultural service and express monetarily this value. It used Contingent Valuation Method to do so. He observed that this manifestation has an economic value, whose willingness to pay per individual participant of the research was $R \$ 34,24$ causing a total of $R \$$ $10.272 .000,00$ (ten million, two hundred and seventy-two thousand reais) in the total universe of the public present in São João on the Island of São Luís MA. The results indicate that the bumba meu boi do Maranhão, for being considered a Cultural manifestation, possesses economic value attributed to its cultural imponence.

KEYWORDS: Valuation of Cultural Events. Bumba Meu Boi. Feast of Saint John. Willingness to Pay. 


\section{Introdução}

O Brasil é um país com dimensões e diversidades culturais ecléticas; sua formação pode ser constituída por vários elementos, como: o europeu, o africano e o indígena. Essa diversificação tem características distintas de região para região, mas são disseminadas pelo país e se transformam em expressão reconhecida como pertencente à nação. Ingold (2000) disserta que pessoas de diferentes contextos culturais percebem a realidade e têm percepções diferentes, uma vez que tais dimensões em termos de quadros alternativos de crenças ou formas de representacionais se relaciona diretamente com a identidade de uma determinada população.

De fato, há várias maneiras de entender a interação homem - meio ambiente - cultura, defini-la e explorá-la; no entanto, as teorias alternativas, analíticas e estratégicas partem de diferentes entendimentos, ou seja, ontologias, epistemologias e métodos, dando origem a uma variedade de enquadramentos de interação complexa. A apreciação e a percepção cultural implicam que argumentos dessa magnitude precisam examinar os enquadramentos disponíveis, a fim de discutir se alguns permitem conceituações mais apropriadas e úteis dos benefícios que o homem obtém do meio ambiente (MOON et. al. 2014).

Ao se meditar sobre o processo, denota-se a atenção para alguns aspectos da controvérsia que está em torno do uso do conceito de Serviços Ecossistêmicos Culturais (SEC) cujo enquadramento é associado à cultura e aos seus valores por ter princípios baseados em suas próprias descrições. Os Serviços Ecossistêmicos (SEC) podem ser considerados como um quadro conceitual, enfatizado por Schröter et al. (2014), que se destina a capturar os benefícios do meio ambiente para a sociedade e, consequentemente, capaz de dar bem-estar humano através da avaliação monetária e dos valores não monetários das funções dos ecossistemas (MEA, 2005a; Pascual et al., 2010).

Os benefícios da natureza implicam várias escolhas normativas que fazem a aplicação SEC; tais escolhas são, fundamentalmente, políticas (KULL et al. 2015). De forma associada, MEA (2005a) destaca a subcategoria de serviços ecossistêmicos culturais que define como benefícios não materiais as pessoas que obtêm dos ecossistemas o enriquecimento espiritual, o desenvolvimento cognitivo, a reflexão, a recreação e as experiências estéticas. Tal teoria é reforçada por Milcu et al. (2013) que consideram particularmente difícil operacionalizar sua essência devido às causas de sua intangibilidade. Em aplicações do conceito do SEC, os autores Fraser et al. (2016), Kull et al. (2015), Daniel et al. (2012) assumem que os valores socioculturais podem ser quantificáveis e correlacionáveis às funções ambientais e às estruturas que escondem conflitos não resolvidos sobre a fusão de valores "não materiais" com benefícios calculáveis do SEC.

A explicação satisfatória sobre os benefícios culturais, em que as pessoas derivam de lugares, processos ou eventos, é exposta por Fraser et al. (2016); para eles, os benefícios de um lugar dependem do tipo do lugar e do serviço que dão origem e não podem ser vistos como uma função separada. Em consonância com os conceitos do SEC, a variável cultural pode ser compreendida como expressão oriunda da própria cultura e suas formas de se manifestar, dentre elas destaca-se o bumba meu boi cuja manifestação, em si, tem a capacidade de produzir conhecimentos através de seus cânticos, danças e do artesanato, havendo, assim, 
uma agregação de elementos que compõe toda a cultura representativa através de um gênero ou de uma ramificação da cultura brasileira.

No Brasil, foram identificados alguns grupos (brincadeiras) de boi em regiões e estados distintos, como: em Santa Catarina (Boi de mamão); Rio Grande do Norte (Boi- calemba); Ceará (Boi-surubi); Rio de Janeiro (Boizinho); Pará/Amazonas (Boibumbá); São Paulo / Rio Grande do Sul (Boizinhos); Alagoas, Bahia, Espírito Santo, Maranhão, Pernambuco, Piauí e Rondônia (Bumba meu boi) (IPHAN, 2011).

O trabalho tem por objetivo mensurar o valor econômico dos serviços ecossistêmicos culturais do "bumba meu boi" do Maranhão, através do Método de Valoração Contingente, para medir o quanto as pessoas estariam dispostas a pagar para assistirem às apresentações da referida manifestação.

\section{Referencial Teórico}

Para atingir os objetivos previamente definidos, o presente trabalho foi dividido em cinco partes: a introdução, em que estão os objetivos, as justificativas, a relevância do tema e breves considerações sobre a temática; o referencial que constitui a moldura teórica e apresenta: revisão da literatura sobre alguns conceitos de aspectos gerais sobre os Serviços Ecossistêmicos, a Cultura e o Patrimônio Cultural, além do Bumba meu Boi do Maranhão e a Valoração Ambiental; em seguida, serão apresentados os resultados e a discussão dos dados para que se possa chegar ao objetivo proposto; finalmente, apresentam-se as conclusões e sugestões.

Para a compreensão do assunto, é necessário entender como a manifestação bumba meu boi é reconhecida como sendo um dos elementos do Serviço Ecossistêmico (SEC), alinhada à variável cultural e suas abordagens conceituais da cultura e do patrimônio cultural. Dessa forma, o processo de valoração ambiental é uma ferramenta que pode auxiliar na atribuição de valor de um bem intangível, representado pelo bumba meu boi.

\section{Serviços Ecossistêmicos}

Devido à preocupação em compreender, de forma mais sistêmica, os serviços ambientais e mensurá-los, foram produzidos quatro importantes documentos. Costanza et al. (2017) citam que são: Millennium Ecosystem Assessment (MEA); The Economics of Ecosystems and Biodiversity (TEEB), Common International Classification of Ecosystem Services (CICES) e Science and policy for people and nature (IPBES). Assim, os Serviços Ecossistêmicos (SEC) são entendidos como benefícios diretos e indiretos, obtidos pelo homem, a partir dos ecossistemas (MEA, 2005b).

Esses documentos contribuíram para o desenvolvimento de metodologias com diferentes escopos; essas divergências produzem tensões como a contradição da definição de MEA. Os Serviços Ecossistêmicos (SEC) são os benefícios que as pessoas obtêm dos ecossistemas (MEA, 2005a); já Haines-Young e Potschin (2016) entendem SEC como as contribuições que o meio ambiente oferece para o bemestar humano e estão mais alinhados ao The Economics of Ecosystems and Biodiversity (2010). 
O quadro conceitual dos serviços ecossistêmicos, atualmente utilizado por Groot, Wilson, Boumans (2002), Haines, Potschin (2013), MEA (2005a) e Teeb (2010), aponta seus elementos como sendo: Habitat ou Suporte, Informação, Provisão; Regulação ou Manutenção; e os Serviços Culturais, estes últimos responsáveis pelo bem-estar social e espiritual do indivíduo. Esses elementos são essenciais para a contribuição em termos de oferta de bens e materiais que garantem uma vida digna, saúde, relações sociais etc. Entretanto, apesar da importância da variável cultural, Daniel et al. (2012) e Milcu et al. (2013) apontam que ela não tem recebido a devida atenção, ou seja, é pouco estudada. Nessa linha, o trabalho de Kumar, Esen e Yashiro (2013) expõem que o SEC deve ser valorizado e incorporado nos processos de valoração, pois se relaciona com o meio ambiente.

De forma complementar, Hacker, Kelemen e Behn (2015) e Kebede et al. (2015) realizaram um extenso trabalho para sistemizar, dentro do contexto europeu, as principais metodologias para a valoração dos serviços ecossistêmicos culturais. No contexto latino-americano, existem iniciativas pontuais como o trabalho desenvolvido por Araújo, Oliveira Júnior e Azevedo (2015); ao se saber isso, reconhece-se que a Valoração dos Serviços Ecossistêmicos, por apresentar uma base de teorias e estudos em processo de desenvolvimento dentro da variável cultural, trata como relevante o processo de planejamento por parte dos gestores e agentes da cultura.

\section{Cultura e Patrimônio Cultural}

Toda sociedade, organizada ou não, simples ou complexa, tem sua cultura dentro do arcabouço universal. O ser humano é considerado culto e a cultura é um atributo do gênero homo; consequentemente, a cultura é um projeto historicamente criado para viver. Assim, as gerações criam novos elementos que são adicionados a ela e isso é responsável pelo desenvolvimento e pela mudança na cultura. Entretanto, a cultura contemporânea combina algo que foi criado pelos antepassados e adicionado pelas novas gerações. Kumar e Hasnain (2017) abordam diferentes definições de "cultura" e refletem diferentes bases teóricas para a compreensão ou critérios para avaliar a atividade humana. O patrimônio é uma construção social que serve sempre a um determinado fim: econômico, simbólico ou político. Para Peralta (2003), os patrimônios são compostos por determinados aspectos da cultura resgatados de um "corpus cultural e sujeitos a uma engenharia social que Ihes confere valor e significado".

No entanto, cultura é um conjunto das práticas, técnicas, símbolos e dos valores que são transmitidos às gerações no sentido de garantir a reprodução de um estado de coexistência social (BOSI, 2002); quanto aos valores, estão os gestos, o idioma, as vestimentas e a expressão artística, dentre outros. No limiar do século $\mathrm{XXI}$, a cultura emerge como variável relevante para a compreensão da complexa relação homem-natureza-sociedade; Hirons et al. (2016) destacam que estudos demonstram que os SEC são essenciais para a identidade cultural e até mesmo para a sobrevivência entre muitas comunidades.

O Patrimônio Cultural pode ser definido como práticas, representações, expressões, conhecimentos, habilidades (como os instrumentos, objetos, artefatos e espaços associados com eles) que comunidades, grupos e, em alguns casos, os indivíduos reconhecem como parte integrante de seu "patrimônio cultural", assim profere UNESCO (2010). Os indivíduos, de fato, reconhecem tal patrimônio como 
parte de sua herança cultural, que é transmitida por gerações, sendo constantemente recriada por comunidades em respostas ao seu ambiente, sua interação com a natureza e a sua história, fornecendo-Ihes um sentido de identidade e continuidade (STEFANO; DAVIS, 2017).

A definição, adotada por Martins (2011), em relação ao patrimônio cultural, diz que é o conjunto de bens, materiais e imateriais, de interesse coletivo, suficientemente relevante e capaz de perpetuar-se ao longo do tempo; sendo o patrimônio a capacidade de fazer recordar o passado, ou seja, uma manifestação, um testemunho, uma invocação, uma convocação do passado, ele tem a função de (re)memorar acontecimentos importantes. Por todo o exposto, o patrimônio cultural imaterial compreende as expressões de vida e tradições que comunidades, grupos e indivíduos recebem de seus ancestrais e passam, em forma de conhecimento, a seus descendentes (UNESCO, 2010). No estado do Maranhão, há duas manifestações reconhecidas pelo Instituto do Patrimônio Histórico e Artístico Nacional (IPHAN), denominadas de Complexo Cultural do Bumba meu Boi e o Tambor de Crioula.

\section{Bumba meu boi do Maranhão}

Localizado entre a Região Amazônica e o Nordeste do país, o estado do Maranhão, por muito tempo, permaneceu isolado do restante do Brasil e, no período colonial, constituiu-se, por mais de uma vez, uma província separada do restante da nação. Nos estudos de Ferreti (2016), o isolamento fez com que nele se desenvolvessem características culturais específicas e diferentes de outras áreas; dentre essas características, surgiu o bumba meu boi cujos indícios se deram por volta do século XVIII na capital maranhense e em cidades circunvizinhas. Assim, Cardoso (2016) e Borralho (2018) citam que essa tradição é uma expressão de teatro popular, viva, que se reinventa, que se transforma, assume novos valores, ressignifica espaços e modifica os sujeitos e sociedades que nele encontram um ponto de preocupação com o outro.

O enredo originou-se a partir de um fato histórico em que Pai Francisco, escravo e vaqueiro de confiança de seu amo, o dono da fazenda, é obrigado a furtar o boi, famoso pelas suas qualidades e pela sua valentia, que o fazendeiro deu de presente à sua filha e confiou aos cuidados do vaqueiro, e matá-lo. Pai Francisco obedeceu aos apelos e aos "desejos" de Mãe Catirina, sua mulher, que se encontrava grávida e com vontade de comer aquele boi, e matou o animal para satisfazê-la. O fato foi consumado, chega ao conhecimento do amo que, enraivecido, manda fazer sindicância, através de vaqueiros e índios, para descobrir a verdade e o autor do crime. Pai Francisco é encontrado, levado preso e obrigado a dar conta do boi. Segue, então, uma verdadeira via-crúcis cuja finalidade é trazer o animal de volta à vida; são chamados os doutores, os pajés ou curadores que, no sentido de intervir, através de processos mágicos, com a ajuda do Pai Francisco, ressuscitam o boi, que "urra" novamente; diante do contentamento geral, Pai Francisco é perdoado e os brincantes entoam cânticos de louvor, dançam em volta do animal na comemoração desse milagre da ressurreição (LIMA, 2003).

Diante dos fatos, percebe-se que a figura do boi, em si, representava um valor sentimental e financeiro cujo retrato temporal é reconhecido como sendo uma relação social e também econômica. Desse modo, o bumba meu boi está presente em todo o Maranhão, dividido em cinco principais estilos, conhecidos como sotaques 
(estilos, expressões): Matraca, Orquestra, Zabumba, Baixada e Costa de mão (IPEA, 2015). Há mais de 400 grupos, localizados em todo o estado; só em São Luís, nas zonas urbana e rural, esse número chega a 250 grupos de bumba meu boi (IPHAN, 2011).

O bumba meu boi estabelece um ritual que se expande por todo o Maranhão; observa-se, até os presentes dias, a mistura de calendários que envolve os folguedos e as manifestações católicas. Organiza-se, assim, um ritual que contém um ciclo da brincadeira e agrupa cerimônias específicas cujo calendário é geralmente: a) Sábado de Aleluia (primeiro ensaio do boi); b) 13 de Junho, dia de Santo Antônio, (ensaio redondo); c) 23 de Junho, véspera de São João, (ritual de batismo); d) 24 de Junho a 25 de Julho (brincadeiras e apresentações); e) 26 de Julho, dia de Sant'Ana (morte e encerramento da brincadeira). Do nascimento à morte, o período de apresentação do Bumba Boi obedece ao ciclo mítico da vida, o acompanha e o celebra, isto é, tudo que nasce um dia morre, se renova, se transforma (BORRALHO, 2018)

\section{Valoração Ambiental}

O sentido econômico do valor baseia-se na ideia de Stahl Jr et. al. (2007), ou seja, uma possível "disposição de pagar" ou vontade de pagar por um bem ou serviço ecossistêmico pode ser pensada como manifestação comportamental de valores gerais e duradouros, e isso inclui preocupação com o estado ecossistêmico. Já Groot et al. (2002) citam três categorias condicionadas ao valor: ecológico, sociocultural e econômico. O valor ecológico depende da capacidade do ecossistema em fornecer bens e serviços, ele é dependente também de fatores de inter-relações das partes do ecossistema: complexidade e raridade. $O$ valor sociocultural dos benefícios não materiais, fornecidos pelos Serviços Ecossistêmicos, pode ser ligado por sentimentos de enriquecimento espiritual, capazes de desenvolver a capacidade mental e o lazer. Quanto ao valor econômico, este envolve variáveis, como: fluxo de benefícios, resultado, taxas de juros e valor do dinheiro no tempo e custo de oportunidade.

Para tanto, é adotado o Método de Valoração Econômica, realizado com base em técnicas que utilizam pressupostos da microeconomia tradicional concernentes ao comportamento e aos objetivos dos agentes econômicos (ANDRADE; ROMEIRO, 2013); critérios de sustentabilidade e o reconhecimento da complexidade dos processos ecológicos, frequentemente, não são incorporados aos processos de valoração de serviços ecossistêmicos culturais (ANDRADE, 2010).

Borja (2011) ressalta que usar valoração ambiental é uma técnica promissora, porém não existe uma classificação real e universal quanto aos métodos adotados por pesquisadores e o organismo, uma vez que tais métodos de valoração são procedimentos aplicados, com rigor lógico e teórico, que se distinguem pela sua forma de utilização. Para a compreensão, é necessário o entendimento de que o processo de valoração é uma atribuição de valor que mensura, qualitativamente ou quantitativamente, um bem ou um conjunto de bens.

Essa prerrogativa se inscreve no universo das práticas discursivas, portando suas formas de expressão e de legitimação próprias, dentro das correntes da economia, como destaca May (2018), isto é, mesmo sendo uma ação dirigida a uma determinada finalidade, a racionalidade econômica moderna é a maximização do 
rendimento dos investimentos, o processo de valorização e sua implicação no estabelecimento de fins e na avaliação de alternativas e meios; logo tem a valoração como um de seus momentos constitutivos. Martins et al. (2018) comentam que, além do principal fato de que a natureza de bens públicos possui uma concepção imensurável sobre seu valor de compra e venda no mercado, outra particularidade são as diversas versões sobre o seu uso e a sua preservação.

Os métodos comumente usados para avaliar as externalidades são: o Método Preço Hedônicos (MPH), o Método Custo de Viagem (MCV) e o Método de Valoração Contingente (MVC). Segundo Spash (2000), Lee et al. (2013), Van Tonder et al. (2013), o método mais preferido para determinar um valor econômico dos SEC, na literatura, é o método de Valoração Contingente; este método tem sido amplamente utilizado em diferentes setores, como: valorização de espécies em trabalhos de Tisdell e Wilson (2001) e Saayman et al. (2013); e turismo costeiro ou de praia segundo Birdir et al. (2013). Para Scarpa et al. (2000), Lu; Shon, (2012), Yao et al. (2014), Choi e Richie (2014), tem-se o estudo de conservação da floresta e compensações de carbono no setor aéreo. O método MCV foi originalmente proposto por Ciriacy-Wantrup em 1947 e a primeira avaliação ambiental foi realizada por Davis em 1963; a popularidade desse método tem aumentado desde a década de 1990 e continua a crescer.

Ao se tratar da valoração de um recurso cultural como a linguagem, Canziani (2016) diz que emprega duas etapas relevantes, sendo elas: (a) valorizar a utilidade intrínseca do ativo cultural com base em sua forma ou significado de identidade cultural; e (b) valorizar o ativo por sua utilidade extrínseca ou função de turismo. Para Silveira; Cirino; Prado Filho (2013), o Método de Valoração Contingente é uma técnica de valoração econômica aplicada a bens e serviços não existentes no mercado; pessoas são questionadas sobre suas disposições a pagar (DAP) a fim de conservar/corrigir ou a receber (DAR) para aceitar a alteração no fornecimento de um bem ou serviço ambiental, mesmo que nunca o tenha utilizado antes. Desse modo, Gullo; Gregori (2012) reforçam que o método contingente faz uso de consultas estatísticas com a população e que é capaz de captar valores individuais, de uso e não uso, que os indivíduos atribuem a um serviço ecossistêmico.

A principal motivação, relacionada à temática abordada, refere-se à necessidade crescente de integração, de forma direta, com a valoração do SEC; desenvolve-se uma importância técnica e científica, associada a relevantes direcionamentos para o entendimento entre as ciências sociais e ambientais, bem como no processo de gestão (público e privado). Diante da dimensão do tema, a justificativa do estudo fundamenta-se, especialmente, por se considerar a necessidade de se melhorar o conhecimento quanto ao valor econômico agregado ao bumba meu boi, sendo este aspecto fundamental para gestores envolvidos no processo cultural e em outros processos que dinamizam a economia local.

Destaca-se assim a indispensabilidade de implementação de medidas viáveis com base no "valor econômico" para a conservação da cultura local, e isso gera benefícios socioeconômicos e uma rede de informações que envolvem poder público, sociedade civil organizada na busca de soluções de investimento de uso racional para manter viva as tradições culturais do bumba meu boi do Maranhão.

Portanto, acredita-se ser possível, com o uso de metodologias de valoração, mensurar valores que agregados podem ser de grande valia para o fortalecimento de estratégias de fomento do bumba meu boi da llha de São Luís. 


\section{Métodos}

A área de pesquisa foi a cidade de São Luís, capital do estado do Maranhão, composta por outros três municípios. O município de São Luís tem uma população, de acordo com o censo 2010, de 1.014.837, com Índice de Desenvolvimento Humano (IDH) de 0,768 e índice de GINI de 0,61 (PROGRAMA DAS NAÇÕES UNIDAS PARA O DESENVOLVIMENTO, 2013). Nesse município, acontece um dos maiores festejos juninos: o "São João", evento que faz parte de um dos ciclos do bumba meu boi; com uma forte expressão cultural no Maranhão, na região e no Brasil, é reconhecido pela sua riqueza cultural em outros países. O principal atrativo dessa festa é o bumba meu boi.

Os dados documentais foram obtidos a partir das seguintes fontes:

a)Sistema Eletrônico do Serviço de Informação ao Cidadão (e-Sic): foram solicitadas informações inerentes aos números de passageiros que desembarcam na ilha de São Luís por meio da aviação civil e dos sistemas rodoviário, ferroviário, e aquaviário (ferry boat) entre os anos de 2015 e 2018, além do fluxo diário dos anos correspondentes;

b)Instituto do Patrimônio Histórico e Artístico Nacional (Iphan), órgão responsável em acompanhar todo o acervo do patrimônio, seja ele material ou imaterial: foram levantados dados históricos, bem como o número e a identificação de grupos de bumba meu boi existentes no estado do Maranhão, via documento protocolado naquela entidade;

c) Secretaria de Estado da Cultura e Turismo (SECTUR): solicitou-se o levantamento de Edital para habilitação, seleção e contratação de serviços artísticos dos grupos; assim como a programação artística do São João de Todos 2018, executada no âmbito dos Espaços Culturais, coordenados pela SECTUR, no período de 15 de junho a 01 de julho de 2018, nas modalidades artísticas: quadrilha, dança portuguesa, dança do cacuriá, dança do caroço, dança cigana, dança do boiadeiro, pela porco, lelê, lili, dança do coco, baião cruzado, bambaê de caixa, grupos alternativos, shows musicais, bumba meu boi e tambor de crioula.

A aplicação do questionário aos gestores dos grupos de bumba meu boi totalizou 18 (dezoito) entrevistas, e a abordagem foi realizada nos ensaios do bumba meu boi (maio), nos arraias (junho) e nas festividades após o período do São João (julho e agosto). Em alguns grupos, a aplicação do questionário não foi possível em decorrência de integrantes estarem a viajar; outros, por questões de trabalho, não puderam conciliar um horário; e outros devido à distância da sede dos grupos, situada em outras cidades do Maranhão, o que ocasiona a inviabilidade no deslocamento até os respectivos locais.

Também foram pesquisados os brincantes, 68 (sessenta e oito), considerados os personagens dos grupos. A abordagem foi feita nos arraiais, no momento da concentração, onde eram realizados os preparativos, a organização das indumentárias, as maquiagens próximas aos palcos. Alguns se abstiveram de responder aos questionamentos da pesquisa, dizendo que estavam com pressa para se arrumarem. Quanto à entrevista com os brincantes, houve, também, o envolvimento dos músicos e do pessoal de apoio; tais entrevistas foram realizadas nos ensaios (maio) e nos arraiais (junho). 
Inicialmente, para a aplicação do questionário com o público, foi solicitada à administração de alguns shoppings a autorização para a entrevista da pesquisa; no entanto, não foi autorizada. Assim, ela foi realizada somente nos arraiais e totalizou 245 (duzentos e quarenta e cinco) questionários. O contato com o público, para a aplicação da entrevista, dava-se após o término de cada apresentação, momento este em que as pessoas se dispersavam para a compra de comidas e de bebidas. No momento das apresentações, a aplicação do questionário era impossibilitada, pois as pessoas estavam atentas às brincadeiras; então era aguardado o instante até o término ou os intervalos de um grupo para outro, isso acontecia em torno de 10 a 15 minutos.

A identificação dos turistas, nos arraiais, foi observada através de alguns grupos aglomerados, houve uma dedução com relação a isso, ou seja, que se tratava de turistas; outro fato, para identificação, foi que, muitas vezes, os apresentadores dos palcos pediam para as pessoas de outros estados levantarem as mãos e dizerem suas respetivas cidades, tal fato não se repetia em todos os arraiais. Ao todo, foram aplicados 331 (trezentos e trinta e um) questionários, em que foram envolvidos os três grupos da pesquisa: gestores, brincantes e o público. Dados da Polícia Militar do Maranhão informaram que a média de público presente, nas programações do São João, foi de 300.000 (trezentas mil) pessoas (SÃO LUís, 2018).

O estudo zelou pelos princípios éticos, ao garantir a integridade dos participantes e a segurança dos dados, sendo submetido e autorizado pelo Comitê de Ética de acordo com os pareceres no 2.753.000, 2.752.999 e 2.752.993. Após a coleta de dados, empreendeu-se a técnica da análise de conteúdo, a fim de se analisar o que foi verificado e propor discussões.

O instrumento para valorar partiu da teoria do Método de Valoração Ambiental, sendo aplicado o Método de Valor Contingente (MVC). Para a elaboração do questionário, apuração, tratamento e análise dos dados, foram utilizados programas estatísticos para isso.

O Método de Valoração do Serviço Ecossistêmico Cultural aplicado foi o MVC, por meio da DAP; este opera os princípios de valorações de serviços ecossistêmicos para a compreensão do "valor" da manifestação cultural tendo como objetivo mensurar o valor econômico dos serviços ecossistêmicos culturais do "bumba meu boi" do Maranhão. Apresenta, como espaço de pesquisa, a grande São Luís e utiliza o Método de Valoração Contingente para compreender essa complexa relação entre o uso, possibilidades de uso e o valor presente.

Com o objetivo de testar a associação entre as variáveis Disposição a Pagar e Socioeconômicas (renda mensal, faixa etária, escolaridade, turista, estado civil, sexo e gastos no evento), foi realizada análise com o uso do Teste de Spearman, ao considerar o nível de significância de 1\%.

Após encontrar o valor médio da disposição a pagar (DAPM), foi evidenciado o valor econômico total do bem cultural, sendo realizado o cálculo via média ponderada. Motta (2006) ressalta que a técnica é de enorme utilidade à análise, pois possui uma potencialidade de captar o valor de existência. 


\section{Resultados e Discussões}

O levantamento de dados aconteceu durante o mês de junho de 2018, período de realização da festa citada no Maranhão. Para os grupos de bumba meu boi, tal período representa a visibilidade das suas brincadeiras e apresentações. Foram identificados, a partir de informações da Sectur, 54 (cinquenta e quatro) arraiais públicos distribuídos na Região Metropolitana de São Luís (Figura 1); esses locais serviram de palco para as apresentações culturais e para a realização dos festejos. As maiores concentrações de arraiais estão centradas na cidade de São Luís - MA.

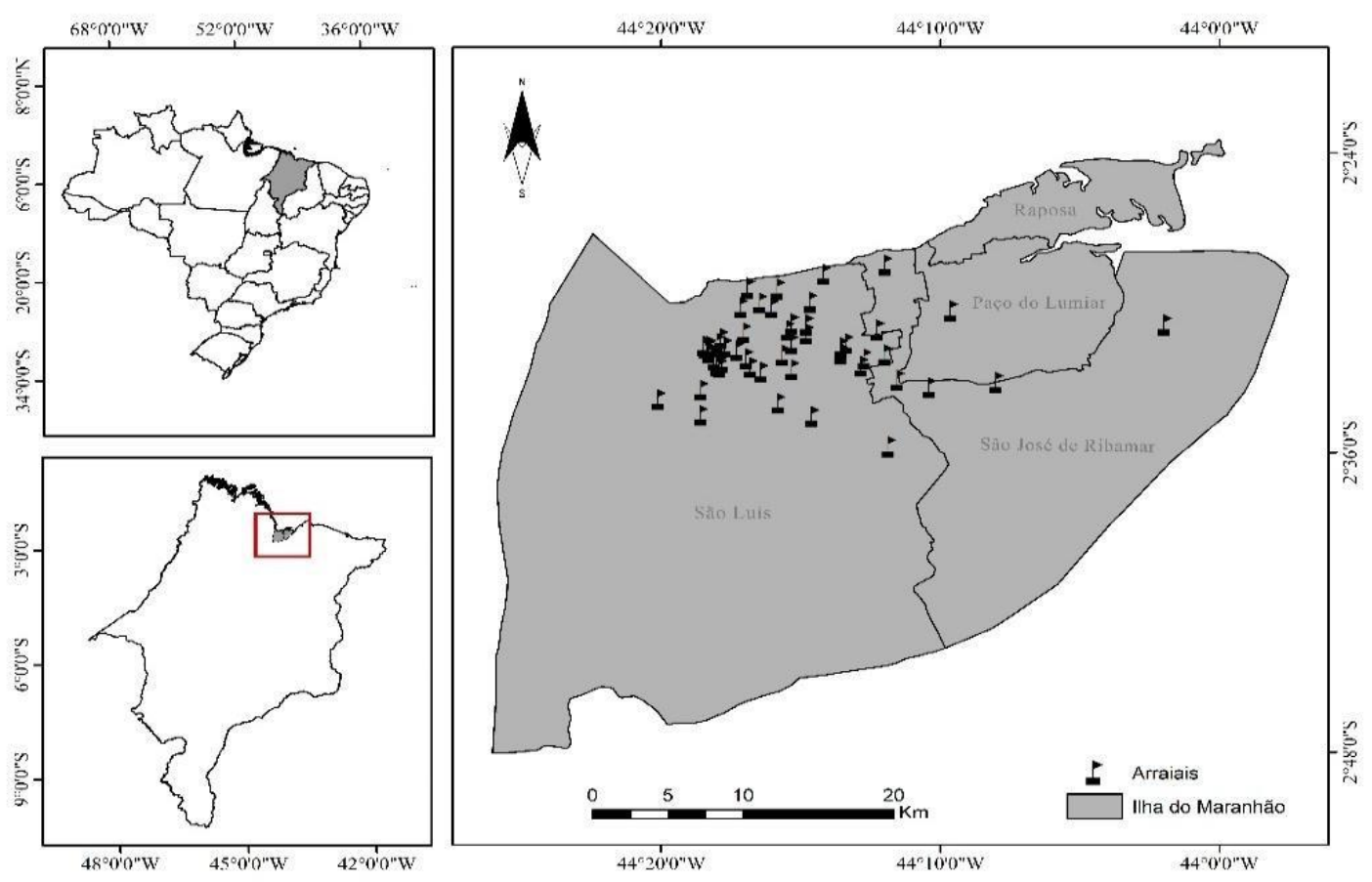

Figura 1: Distribuição de arraiais juninos. Ilha de São Luís, Maranhão, Brasil, 2018 Figure 1: Distribution of june camp sites. São Luís Island, Maranhão, Brazil, 2018

Fonte: Elaborado pelos autores.

Source: Prepared by the authors.

Segundo a classificação, referente ao edital do São João de Todos 2018, foram contemplados 189 grupos de bumba meu boi: 7 (sete), Costa de Mão; 16 (dezesseis), Zabumba; 38 (trinta e oito), Baixada; 34 (trinta e quatro), Matraca; 74 (setenta e quatro) Orquestra; e 20 (vinte) Grupos Alternativos, conforme apresentado na Figura 2. Esses grupos realizavam as apresentações nos arraiais cuja programação ocorreu entre os dias 15 de Junho e 01 de Julho, de 20h até as $22 \mathrm{~h}$. 


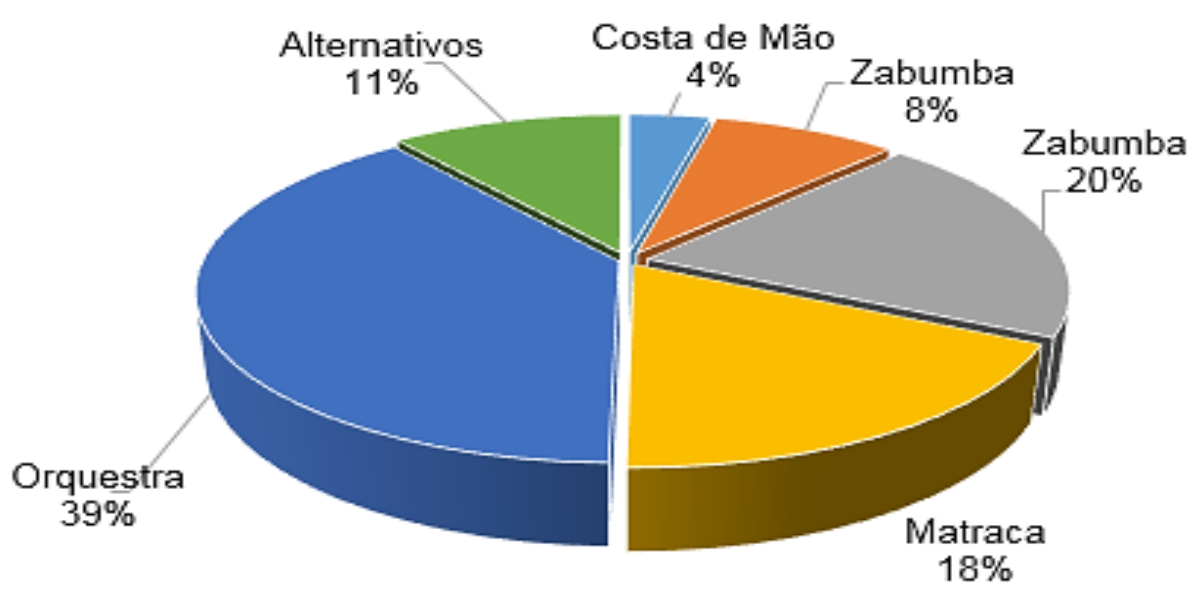

Figura 2: Sotaques credenciados para o São João de Todos 2018.

Figure 2: Accredited accents for St. John of All 2018.

Fonte: Elaborado pelos autores.

Source: Prepared by the authors.

Ainda em relação aos grupos e sotaques classificados para as apresentações, foram definidas categorias (A, B, C) dos grupos de bumba meu boi, elaboradas pela Câmara Técnica do Conselho Estadual de Cultura do Maranhão (Consecma), consequentemente ratificadas pela Sectur. Essas categorias definem os valores dos cachês, sendo que, na CATEGORIA A (pontuação de 150 a 140), o valor de cachê é $R \$ 7.000,00$. Para a CATEGORIA B (pontuação de 139 a 120), o valor do cachê é de $R \$ 6.000,00$. Na CATEGORIA C (pontuação abaixo de 120), o valor é de $R \$ 5.000,00$. O pagamento foi realizado mediante apresentação de comprovante de presença, entregue no ato da apresentação cultural, assinado por um representante da Secretaria, e a apresentação de nota fiscal à Sectur.

$\mathrm{Na}$ Figura 3, demonstra-se quanto cada sotaque recebeu em razão das apresentações. Os grupos do sotaque Costa de Mão são observados pela sua quantidade e classificação e considerados em extinção; com o intuito de valorizar o grupo e evitar o seu desaparecimento, foram lançadas, pelo Iphan e Sectur, medidas que possibilitem a valorização e, com isso, adotou-se que esse tipo de sotaque não participaria do processo seletivo, sendo colocado, diretamente, no quadro de apresentações em todos os arraiais oficiais, abrindo todas as noites da programação do São João. Os sotaques de Zabumba foram classificados apenas na categoria cujo valor total pago, em cachês, foi de $R \$ 112.000,00$; enquanto os sotaques da Baixada, classificados em todas as categorias, recebeu $R \$ 241.000,00$. Os grupos de Matraca, com todas as categorias, receberam $R \$ 218.000,00$; já o sotaque de Orquestra agregou maior quantitativo de grupos, sendo classificado em todas as categorias, valores estes que alcançaram $R \$ 252.000,00$ em cachês. Por fim, os Grupos Alternativos, que não têm classificação de categoria, receberam $\mathrm{R} \$$ $140.000,00$

A Figura 3 demonstra os valores que foram pagos referentes aos cachês das apresentações, nos arraiais, para os grupos de bumba meu boi; isso evidenciou um montante de $\mathrm{R} \$ 1.212 .000,00$. 


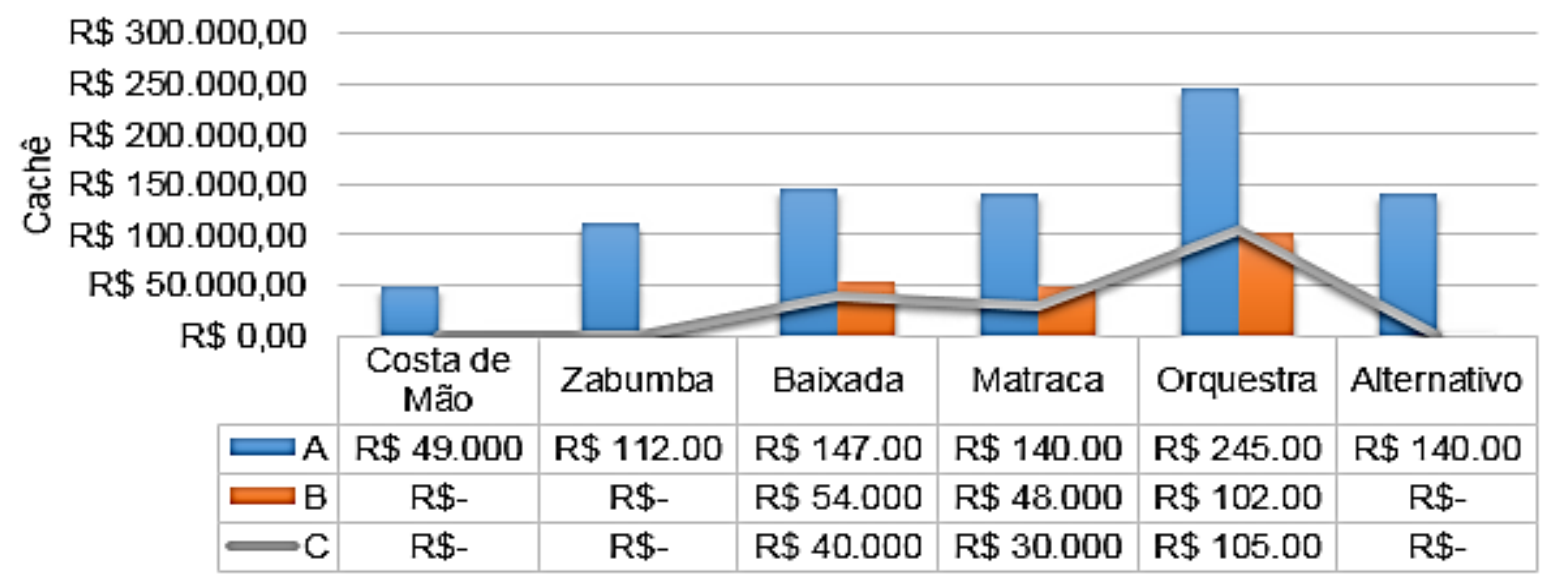

Figura 3: Cachê por Sotaque e Categoria.

Figure 3: Accent and Category Caching.

Fonte: Elaborado pelos autores.

Source: Prepared by the authors.

As manifestações culturais possuem uma dinâmica própria que possibilita a valoração; assim, como aponta Pelegrini (2006), estão em constante transformação. Foram entrevistadas 331 pessoas, divididas em 3 grupos de pesquisa: público (pessoas que frequentaram os arraiais), este grupo correspondeu 245 (75\%) entrevistados; brincantes (dançarinos, músicos e comissão organizadora dos grupos), este grupo alcançou 68 entrevistados (20,5\%); e gestores dos grupos (responsáveis em coordenar e gerenciar) com 18 (5,5\%) do total de entrevistados. A análise descritiva desses grupos foi realizada segundo a faixa etária, o estado civil e a escolaridade conforme a Figura 4.
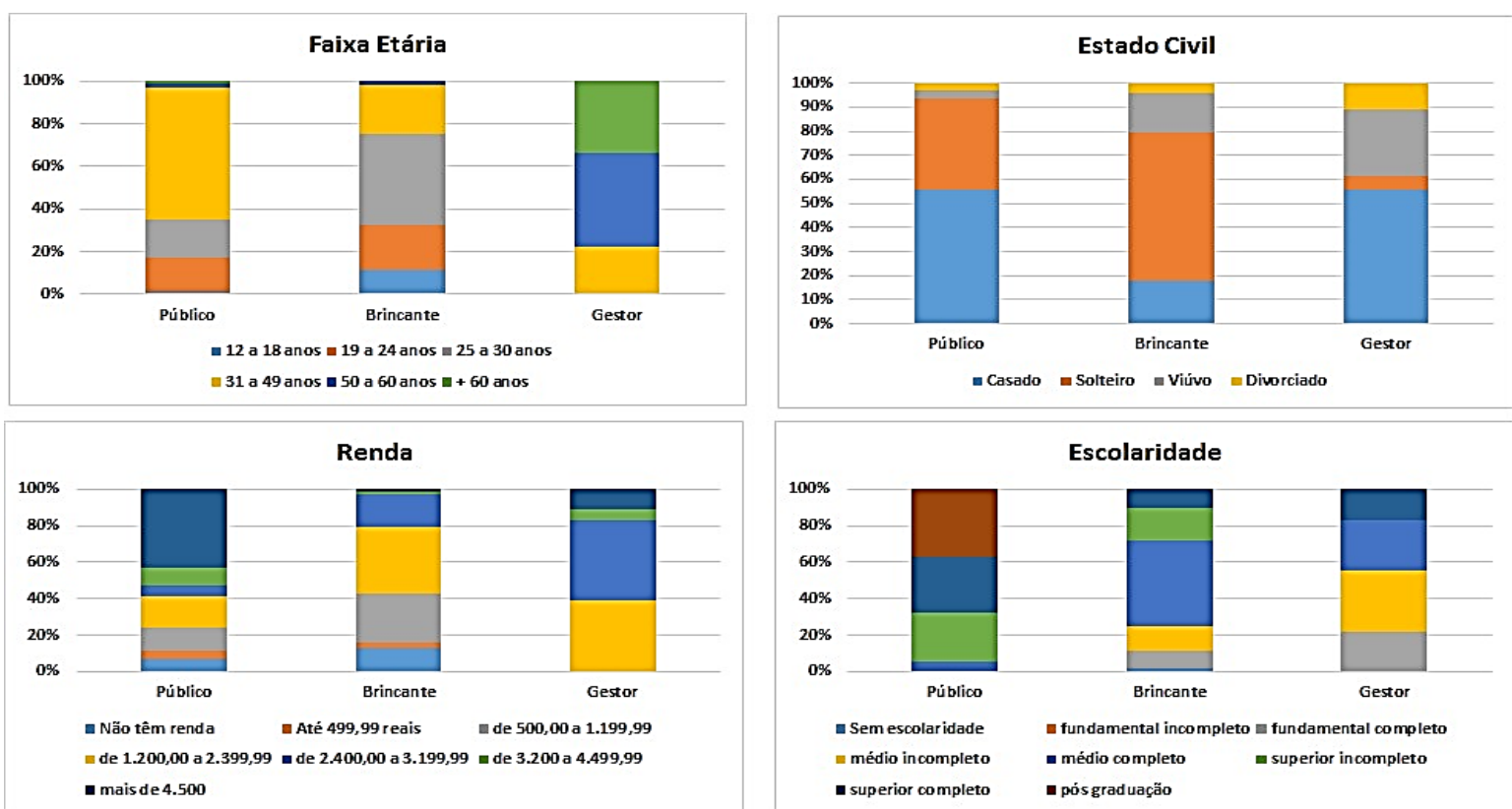

Figura 4: Características socioeconômicas do Público, Brincantes e Gestores segundo faixa etária, estado civil, renda e escolaridade.

Figure 4: Socioeconomic characteristics of the Public, Playmates and Managers according to age group, marital status, income and education

Fonte: Dados da pesquisa realizada pelos autores, em 2018.

Source: Data from the research conducted by the authors in 2018. 
Quanto ao público entrevistado, a faixa etária predominante está entre 31 e 49 anos; já os casados correspondem a $55,5 \%$. Por sua vez, nos brincantes, a faixa etária predominante $(42,6 \%)$ foi a de 25 a 30 anos. Identificou-se a prevalência de solteiros, correspondendo a $61,8 \%$ do total dos entrevistados nesse grupo.

Os gestores dos grupos de bumba meu boi entrevistados concentravam-se na faixa etária entre 50 e 60 anos (44,4\%), eram casados ou em união estável (55\%). Dentre os grupos entrevistados, houve prevalência do sexo masculino entre os gestores (89\%) e brincantes (56\%); não houve prevalência entre os sexos.

No estudo abordado, foram identificados, na pesquisa, 26 turistas, estes representaram $10,6 \%$ do total da amostra do público cuja média, em dias na cidade, correspondeu a 16 dias; destes, 85\% ficaram hospedados em hotéis.

Quanto à renda, identificou-se, entre o público entrevistado, que $43 \%$ ganham acima de $R \$ 4.500,00$. No grupo dos brincantes, identificou-se prevalência de $37 \%$ com renda entre $R \$ 1.200,00$ e 2.399,99 mensais. Já os gestores dos grupos de bumba meu boi da amostra informaram uma renda de $2.400,00$ a 3.199,99 mês $(44,4 \%)$.

A escolaridade, identificada entre os grupos, aponta que, no público, $36,7 \%$ possuem pós-graduação; já entre os brincantes, $47,1 \%$ possuem ensino médio completo. Dentre os gestores entrevistados, o maior percentual concentra-se também no ensino médio $(27,8 \%)$.

Em estudo realizado por Almeida et al. (2017), relativo à avaliação ambiental do Parque Olhos D'Água em Brasília, por referente, contabilizou-se que 95\% dos entrevistados possuem nível superior incompleto, completo ou são pós-graduados. A alta escolaridade constatada pôde ser explicada devido ao fato de ser um local frequentado por muitos professores e estudantes.

Para Conde (2015), a análise comparativa de respostas, por faixa etária, sexo e tempo de residência, pode ajudar a compreender respostas muito divergentes, caso isso seja observado.

Essas diferenças podem ser explicadas pelos distintos indivíduos quanto à predileção da manifestação cultural e também pelo valor que se dá a uma determinada característica física. O modo de ser das pessoas, sua cultura, vai muito além das aparências, do que se reconhece, seja à primeira vista, ou seja, no seu modo de vestir, dos lugares que frequentam, de seus costumes e crenças (IPEA, 2011).

Sobre a Disposição a Pagar, os resultados evidenciaram que, dentre os entrevistados,68,5\% pagariam um valor entre $R \$ 20,00$ (vinte reais) e/ou mais que $R \$ 100,00$ (cem reais); outros pagariam mais de $R \$ 100$, apenas $4,9 \%$ da amostra; e $26,5 \%$ do total da amostra não pagariam conforme descrito na Tabela 1 e baseado no estudo realizado por Báez-Montenegro (2012) no que se refere às comparações internacionais, tendo em conta uma abordagem técnica muito semelhante à forma de pagamento.

No entanto, estudos relatam uma disposição a pagar de 5,75 \$ na cidade de Noto na Sicília (Itália), e 7,5\$ em Quito no Equador conforme Chafla (2019). As diferenças são mais marcantes, provavelmente, devido à abordagem contrastante em relação à forma de pagamento usada nos casos, sendo adotado um novo imposto para cobrir o custo de preservar a cidade. 
Tabela 1: Média de Disposição a Pagar entre o público entrevistado em arraiais juninos. São Luís, 2018. Table 1: Average Willingness to Pay among the interviewed public in june village. St. Louis, 2018.

\begin{tabular}{lcccr}
\hline \multicolumn{1}{c}{ Valores da DAP } & $\mathbf{n}$ & $\%$ & $\begin{array}{c}\text { DAP em relação aos } \\
\text { entrevistados (Público) }\end{array}$ & - \\
\hline Não pagaria & 65 & 26,5 & & 6,44 \\
pagaria Até R\$ 20,00 & 79 & 32,2 & & 13,45 \\
Entre R\$ 20,00 a R\$ 50,00 & 66 & 26,9 & 9,40 \\
Entre R\$ 50,00 a R $\$ 100,00$ & 23 & 9,4 & 4,95 \\
mais R\$ 100,00 & 12 & 4,9 & & 10 \\
\hline
\end{tabular}

Fonte: Dados da pesquisa realizada pelos autores, em 2018.

Source: Data from the research conducted by the authors in 2018.

A Disposição a Pagar média identificada foi de $R \$ 34,24$ para a manifestação cultural do 'bumba meu-boi". Curvina e Freire (2015) aplicaram uma metodologia de Valoração Ambiental, esta realizou a valoração da Festa do Divino pelo Método de Disposição a Pagar; a partir de tal metodologia, encontrou-se 65,38\% de indivíduos dispostos a pagar $\mathrm{R} \$ 31,17$ para desfrutar do evento analisado. Neste estudo, $26,9 \%$ pagariam entre 20 e 50 reais, um valor menor se comparado à Festa do Divino.

Essas diferenças podem estar relacionadas às possíveis diferenças sociais entre os grupos nas cidades e à possibilidade de diferentes formas de incentivos e valorização da cultura local. Sobre isso, o autor Ribeiro (2004) destaca que a formulação de políticas públicas valoriza e aproveita os recursos culturais como forma de valorizar a imagem da festa e perpetuá-la, fato dependente dos interesses de meios oficiais de apoio e de setores com uma ampla visão cultural.

Báez-Montenegro et al. (2012) destacam que a valoração econômica do patrimônio histórico cultural constitui um desafio metodológico, uma vez que estudos estimam seu impacto econômico como atração turística, em que as pessoas estão conscientes do papel do patrimônio como criador de externalidades e apreciam-no como um elemento na identificação coletiva.

Com base na média de público presente no São João no ano de 2018, estimado em 300.000 mil pessoas, e com base no valor da DAPM de $R \$ 34,24$, calculado sobre o universo do público presente, foi encontrado um valor total de $\mathrm{R} \$$ 10.272.000,00 (dez milhões e duzentos e setenta e dois mil reais) da manifestação cultural do bumba meu boi.

O teste de correlação de Spearman foi utilizado para avaliar a correlação entre a disposição a pagar e as características da população estudada; uma conexão positiva foi observada entre as variáveis Disposto a Pagar e ser Turista, também (Tabela 2). 
Tabela 2: Coeficientes de Correlação de Spearman entre as variáveis de disposição a pagar e a variável socioeconômicas pela participação no Bumba meu Boi.

Table 2: Spearman correlation coefficients between willingness to pay and socioeconomic variables for participation in Bumba meu Boi.

\begin{tabular}{ccc}
\hline Variáveis & $\begin{array}{c}\text { Correlação } \\
\text { (p) }\end{array}$ & $\begin{array}{c}\text { Grau de correlação } \\
\text { / sentido }\end{array}$ \\
\hline Disposto a pagar $\sim$ Renda Mensal & $-0,057$ & Fraca negativa \\
Disposto a pagar $\sim$ Faixa etária & $-0,028$ & Fraca negativa \\
Disposto a pagar $\sim$ Escolaridade & $-0,053$ & Fraca negativa \\
Disposto a pagar $\sim$ Turista & $0,381^{\star *}$ & Fraca positiva \\
Disposto a pagar $\sim$ Estado civil & 0,094 & Fraca positiva \\
Disposto a pagar $\sim$ Sexo & 0,026 & Fraca positiva \\
Disposto a pagar $\sim$ Gastos no evento & $-0,204^{\star \star}$ & Fraca negativa \\
Bisposto a pagar $\sim$ importância preservar a cultura & $0,381^{\star \star}$ & Fraca positiva \\
\hline Bumba Boi &
\end{tabular}

${ }^{\star \star}$ Coeficientes de Correlação estatisticamente significativos (Valor-p $<0,01$ )

Fonte: Dados da pesquisa realizada pelos autores, em 2018.

Source: Data from the research conducted by the authors in 2018.

De forma resumida, o teste de Spearman, apresentado na tabela 3, tem índice de confiança de $95 \%$ e o valor de $p=<0,01$; sendo assim, é possível verificar que a correlação entre as variáveis "Disposição a Pagar" e ser "Turista" é estatisticamente significativa ao nível de 0,01 ( $p$-valor=0,381) e tem um coeficiente de correlação positivo. Isso indica que quanto maior o número de turista maior a disposição a pagar, maior também será o reconhecimento da manifestação cultural.

Os ativos culturais, segundo Canziani (2016), podem ter alta utilidade intrínseca quando a maioria das partes interessadas atribui alto valor à representação do bem cultural. Os ativos culturais têm alta utilidade extrínseca se existir uma oportunidade econômica para a troca do bem cultural por algo de valor.

Por fim, existe uma correlação estatisticamente significativa entre as variáveis "Disposição a Pagar" e "Gastos no Evento"; isso também é estatisticamente significativo ( $p$-valor $=0,381$ ), pois há uma tendência de quanto maior os gastos, nos eventos, maior será a disposição a pagar.

Estudos realizados por Hildebrand, Graça e Hoeflich (2002) encontraram uma tendência maior em não pagar quando o morador é local, ou seja, o turista está mais disposto a realizar o pagamento do que a comunidade nativa. Já para Pereira (2009), o pagamento por serviços ambientais, aliando conservação e ecoturismo, constatou que a disposição dos turistas em contribuir com recurso financeiro, para pagamento de serviços ambientais, é de $56 \%$ e é favorável, mas vários desses turistas ressaltam a necessidade de um projeto transparente em relação à captação e à destinação de recursos; sendo assim, eles estariam dispostos a pagar, ao sugerir uma taxa/tarifa média de $R \$ 1,60$ por pessoa/dia, variando de $R \$$ 0,50 a $R \$ 15,00$.

\section{Conclusões}

Mensurar os serviços ecossistêmicos culturais pode contribuir para uma melhor distribuição de recursos públicos, bem como para a formulação e a implementação de políticas públicas voltadas à cultura. O presente trabalho auxilia na reflexão sobre a valoração dos serviços ecossistêmicos culturais do bumba meu boi do Maranhão. O objetivo da pesquisa foi identificar o valor econômico (um dos 
propósitos do SEC) por meio da disposição a pagar. A construção da metodologia ainda está fortemente arraigada aos princípios da valoração de serviços ecossistêmicos ambientais, sendo, portanto, uma limitação da presente pesquisa.

Identificou-se que, em relação à disposição a pagar, os turistas são os que mais estão disponíveis a realizar pagamento para os espetáculos do bumba meu boi. A média do valor da Disposição a Pagar encontrada foi de $R \$ 34,24$ (trinta e quatro reais e vinte e quatro centavos); esse valor é próximo dos valores de peças de teatro e shows que acontecem em São Luís, estes que seriam produtos concorrentes em termos de consumo cultural. Pelas estimativas de público, o valor foi estimado em $R \$ 10.272 .000,00$ (dez milhões e duzentos e setenta e dois mil reais); entretanto, uma outra limitação da pesquisa permite inferir que esse valor seja bem superior ao estimado, isso porque são mais de 40 arraiais que acontecem na cidade. Estes, ocorrem em espaços públicos e privados, sendo que, nos ambientes privados, não foi possível aplicar a pesquisa.

$\mathrm{Na}$ análise de serviços ecossistêmicos, deve-se considerar, também, os efeitos positivos economicamente, mesmo para as pessoas que não gostam do bumba meu boi, pois seus benefícios giram em retorno ou ganho que gera um desenvolvimento na economia local. Assim, entende-se que a análise econômica e social é relevante para o entendimento e para a concepção do valor de valoração do bem cultural.

Apesar do esforço dos pesquisadores, a pesquisa apresenta algumas limitações, dentre elas a definição da amostra do número de turistas; esta pode ser considerada um fator limitante tendo em vista não existir um bom número de participantes, pois ficou inviabilizada a identificação deles nos arraiais. Outra limitação importante foi a aplicação do questionário com os brincantes e gestores dos grupos de bumba meu boi devido ao pouco tempo que tinham para a entrevista, pois deslocavam-se rapidamente de um arraial para o outro.

Conclui-se, também, diante das análises, que o bumba meu boi do Maranhão é uma manifestação cultural rica por causa de seus valores sentimentais, históricos, culturais e, consequentemente, é reconhecido por meio de métodos valorativos que demonstraram o seu valor econômico; assim sendo, é responsável por dinamizar a cultura do povo do Maranhão e fazer crescer a economia local, porque envolvem, nos festejos juninos, vários setores da economia.

Por fim, conclui-se que, diante de toda exposição, permanece o desafio de mensurar outras manifestações culturais, dentro da variável cultural dos Serviços Ecossistêmicos, de âmbito nacional e internacional, que atendam não somente às expectativas dos agentes culturais, mas ao interesse no desenvolvimento e na evidenciação do valor cultural, e que proporcione uma interpretação clara quanto ao seu significado a fim de contribuir, dessa forma, para a adoção de políticas, de planejamento e de tomada de decisões coerentes, e para o debate sobre a mensuração do patrimônio cultural, o bumba meu boi. 


\section{Referências}

ALMEIDA, A. N. et al. Avaliação ambiental do parque Olhos D’Água: aplicação do método da disposição a pagar. Floresta e Ambiente, Rio de Janeiro, v. 24, p.1-12, 2017.

ANDRADE, D. C. Modelagem e valoração de serviços ecossistêmicos: uma contribuição da economia ecológica. Instituto de Economia, Universidade Estadual de Campinas, Campinas. p, 1-269, fev. 2010.

ANDRADE, D. C.; ROMEIRO, A. R. Valoração de serviços ecossistêmicos: por que e como avançar? Sustentabilidade em Debate, Brasília, DF, v. 4, n. 1, p. 43-58, jul. 2013.

ARAÚJO, H. R.; OLIVEIRA JÚNIOR, A. F.; AZEVEDO, A. A. Valoração de serviços ambientais: subsídio para a sustentabilidade do atrativo natural Gruta do Salitre, Diamantina, Minas Gerais. Pesquisas em Turismo e Paisagens Cársticas, Campinas, v. 8, n. 1, p. 17-26, 2015.

BÁEZ-MONTENEGRO, A. et al. Inhabitants' willingness to pay for cultural heritage: a case study in Valdivia, Chile, using contingent valuation. Journal of Applied Economics, v. 15, n. 2, p. 235-258, 2012.

BIRDIR, S. et al. Willingness to pay as an economic instrument for coastal tourism management: cases from Mersin, Turkey. Tourism Management, Frenchs Forest, v. 36, p. 279-283, June. 2013.

BORJA, O.R.P. Ecoturismo responsável: valoração econômica de bens e serviços ambientais. Revista Brasileira de Ecoturismo. São Paulo, v.4, n.3, 2011, pp.345360.

BORRALHO, T. Os elementos animados no Bumba-meu-boi do Maranhão. MóinMóin: Revista de Estudos sobre Teatro de Formas Animadas. Florianópolis, v. 1, n. 2, p. 156-178, 2018.

BOSI, A. Dialética da colonização. 4. Ed. São Paulo: Companhia das Letras, 2002.

BRASIL, UNESCO. Organização das Nações Unidas para a Educação, a Ciência e a Cultura. Educação: um tesouro a descobrir. Relatório para UNESCO da Comissão Internacional sobre Educação para o Século XXI. Tradução Guilherme João de Freitas Teixeira. Brasília, DF, 2010.

CANZIANI, B.F. et al. Cultural resource valuation in tourist destina-tions. Annals of Tourism Research, v. 61, p. 22-24, 2016.

CARDOSO, L. C. M. Mestre Marcelino Azevedo: uma história de resistência contada nas zabumbas do Bumba meu Boi. Revista Internacional de Folkcomunicação. Ponta Grossa, v. 14, n. 31, p. 165-174, 2016.

CHAFLA MARTINEZ, Pablo.La disposición al pago para la conservación de bienes patrimoniales: caso del centro histórico de la ciudad de quito. Cuadernos de Economia. [online]. 2019, vol.38, n.76, pp.231-257. ISSN 0121-4772.

CHOI, A. S.; RICHIE, B. W. Willingness to pay for flying carbon neutral in Australia: an exploratory study of offsetter profiles. Journal of Sustainable Tourism. London, v. 22, p. 1236-1256, 2014.

CONDE, K. M. Dimensões urbanas e percepção de valor socioambiental em bairros habitacionais: o caso de Vitória - ES. UNICAMP: Campinas, 2015. 230 pp. 
COSTANZA, R. et al. Twenty years of ecosystem services: How far have we come and how far do we still need to go? Ecosystem Services, Erscheinungsort nicht ermittelbar. v. 28, p. 1-16, 2017.

CURVINA, V.M.G.; DE SOUZA FREIRE, F. MENSURAÇÃO DE EVENTOS CULTURAIS: Estudo aplicado na Festa do Divino em Pirenópolis-GO. Anais do Congresso Brasileiro de Custos-ABC. 2015.

DANIEL, T.C. et al. Contributions of cultural services to the ecosystem services agenda. Proceedings of the National Academy of Sciences, v. 109, n. 23, p. 8812-8819, 2012.

FRASER, J.A. et al. Cultural valuation and biodiversity conservation in the Upper Guinea forest, West Africa. Ecology and Society, v. 21, n. 3, 2016.

FERRETTI, S.F. Encantaria Maranhense de Dom Sebastião. Revista Lusófona de Estudos Culturais, v. 1, n. 1, p. 262-285, 2016.

GROOT, R. S.; WILSON, M. A.; BOUMANS, R. M. A typology for the classification, description and valuation of ecosystem functions, goods and services. Ecological Economics, New York, v. 41, n. 3, p. 393-408, 2002.

GULLO, M.; GREGORI, L. Valoração de recursos ambientais: uma análise do método de valoração contingente aplicado à coleta dos resíduos sólidos seletivos na cidade de Caxias do Sul. In: RECH, A. U.; BURZKE, A.; GULLO, M. C. (Orgs.). Direito, economia e meio ambiente: olhares de diversos pesquisadores. Caxias do Sul: Educs, 2012.

HACKER, B. R.; KELEMEN, P. B.; BEHN, M. D. Continental lower crust. Annual Review of Earth and Planetary Sciences. Palo Alto, v. 43, p. 363-404, May. 2015.

HAINES-YOUNG, R.; POTSCHIN, M. Defining and measuring ecosystem services. In: POTSCHIN, M. et al. Routledge handbook of ecosystem services. London: Routledge. p. 53-72. 2016.

HILDEBRAND, E.; GRAÇA, L. R.; HOEFLICH, V. A. Valoração contingente na avaliação econômica de áreas verdes urbanas. Revista Floresta, Curitiba, v. 32, n. 1, p. 121-132, 2002.

HIRONS, M.; COMBERTI, C.; DUNFORD, R. Valuing cultural ecosystem services. Annual Review of Environment and Resources, Palo Alto, v. 41, p. 545-574, 2016.

INGOLD, T. The perception of the environment: essays on livelihood, dwelling and skill. Routledge, 2002.

INSTITUTO DE PESQUISA ECONÔMICA APLICADA. Caracterização e quadros de análise comparativa da governança metropolitana no Brasil: análise comparativa das funções públicas de interesse comum (Componente 2). Rio de Janeiro, 2015.

INSTITUTO DO PATRIMÔNIO HISTÓRICO E ARTÍSTICO NACIONAL. Complexo Cultural do Bumba-meu-boi do Maranhão: dossiê do registro como Patrimônio Cultural do Brasil. São Luís, 2011.

KEBEDE, A. S. et al. Direct and indirect impacts of climate and socio-economic change in Europe: a sensitivity analysis for key land-and water-based sectors. Climatic Change, v. 128, n. 3/4, p. 261-277, 2015. 
KUMAR, P.; ESEN, E. S.; YASHIRO, M. Linking ecosystem services to strategic environmental assessment in development policies. Environmental Impact Assessment Review, New York, v. 40, p. 75-81, 2013.

KUMAR, K. Anil; ROY, Debal Singha; HASNAIN, Nadeem. Block-2 Society And Culture. 2017.

KULL, C.A.; DE SARTRE, X. A.; CASTRO-LARRAÑAGA, M. The political ecology of ecosystem services. Geoforum, v. 61, p. 122-134, 2015.

LEE, W. S.; GRAEFE, A. R.; HWANG, D. Willingness to pay for an ecological park experience. Asia Pacific Journal of Tourism Research, London, v. 18, n. 3, p. 288302, 2013.

LU, J. L.; SHON, Z. Y. Exploring airline passengers' willingness to pay for carbon offsets. Transportation Research Part D Transport and Environment, Exeter, v. 17, n. 2, p. 124-128, 2012.

LIMA, Carlos. O universo do Bumba-meu-boi do Maranhão. Olhar, memória e reflexões sobre a gente do Maranhão. São Luís: CMF, 2003.

MARTINS, O. et al. Uma discussão conceitual sobre o tratamento contábil dos heritage assets. Contexto, Porto Alegre, v. 14, n. 26, p. 66-78, jan./abr. 2014.

MARTINS, S.D.T. A memória de um lugar: discursos e práticas identitárias na freguesia do Castelo em Lisboa. 2011. Tese de Doutorado. Instituto Superior de Ciências Sociais e Políticas.

MILCU, A. I. et al. Cultural ecosystem services: a literature review and prospects for future research. Ecology and Society, Wolfville, v. 18, n. 3, p. 44, 2013.

MILLENNIUM ECOSYSTEM ASSESSMENT (MEA). Ecosystems and human wellbeing: biodiversity synthesis. Washington, DC: World Resources Institute, 2005a.

MILLENNIUM ECOSYSTEM ASSESSMENT (MEA). Ecosystems and human wellbeing: Wetlands and water. Washington, DC: World Resources Institute, 2005b.

MOON, K. et al. A guideline to improve qualitative social science publishing in ecology and conservation journals. Ecology and Society, v. 21, n. 3, 2016.

MOTTA, R. S. Economia ambiental. Rio de Janeiro: FGV Editora, 2006.

PASCUAL, $U$. et al. The economics of valuing ecosystem services and biodiversity. The economics of ecosystems and biodiversity: ecological and economic foundations, p. 183-256, 2010.

PERALTA, E. O Mar por Tradição: o Patrimônio e a Construção das Imagens do Turismo. Horizontes Antropológicos, Porto Alegre, v. 9, n. 20, p. 83-96, 2003.

PEREIRA, M. A.; CAMPOS, W. G. Pagamento por serviços ambientais aliando conservação e Ecoturismo. Revista Brasileira de Ecoturismo. São Paulo, v.2, n.3, 2009, pp.255-272.

PELEGRINI, S. C. A. Cultura e natureza: os desafios das práticas preservacionistas na esfera do patrimônio cultural e ambiental. Revista Brasileira de História, São Paulo, v. 26, n. 51, p. 115-140, 2006.

PROGRAMA DAS NAÇÕES UNIDAS PARA O DESENVOLVIMENTO. Atlas do Desenvolvimento Humano no Brasil: São Luís, MA. 2013. 
RIBEIRO, M. Festas populares e turismo cultural-inserir e valorizar ou esquecer? O caso dos Moçambiques de Osório, Rio Grande do Sul. Pasos: Revista de Tursmo y Patrimonio Cultural, Islas Canarias, v. 2, n. 1, p. 47-56, 2004.

SAAYMAN, A. et al. Exchange rate volatility and tourism-revisiting the nature of the relationship. European Journal of Tourism Research, Sofia, v. 6, n. 2, p. 104-121, 2013.

SÃO LUÍS. Prefeitura Municipal. Arraial da Maria Aragão registra recorde de público na noite de quinta-feira (28). Agência São Luís, São Luís, 29 jun. 2018. Disponível em: <http://www.agenciasaoluis.com.br/noticia/21841/>. Acesso em: 10 set. 2018.

SCARPA, R. et al. Valuing the recreational benefits from the creation of nature reserves in Irish forests. Ecological Economics, v. 33, n. 2, p. 237-250, 2000.

SILVA, A. B. Contribuição ao estudo do folclore amazônico na zona bragantina. Boletim do Museu Paraense Emílio Goeldi, Belém, n. 5, 1959.

SILVEIRA, V. C.; CIRINO, J. F.; PRADO FILHO, J. F. do. Valoração econômica da área de proteção ambiental estadual da Cachoeira das Andorinhas-MG. Revista Árvore, Viçosa, MG, v. 37, n. 2, p. 257-266, 2013.

SCHRÖTER, M. et al. Ecosystem services as a contested concept: a synthesis of critique and counter-arguments. Conservation Letters, v. 7, n. 6, p. 514-523, 2014.

SPASH, C. L. Multiple value expression in contingent valuation: economics and ethics. Environmental Science and Technology, Washington, DC, v. 34, n. 8, p. 1433-1438, 2000.

STAHL JR, Ralph G. et al. Valuation of Ecological Resources: Integration of Ecology and Socioeconomics in Environmental Decision Making. CRC Press, 2007.

STEFANO, M. L.; DAVIS, P. The Routledge companion to Intangible Cultural Heritage. London: Routledge, 2017.

THE ECONOMICS OF ECOSYSTEMS AND BIODIVERSITY. Mainstreaming the economics of nature: a synthesis of the approach, conclusions and recommendations of TEEB. Geneva: UNEP TEEB, 2010.

TISDELL, C.; WILSON, C. Wildlife-based tourism and increased support for nature conservation financially and otherwise: evidence from sea turtle ecotourism at Mon Repos. Tourism economics, v. 7, n. 3, p. 233-249, 2001.

VAN TONDER, C.; SAAYMAN, M.; KRUGELL, W. Tourists' characteristics and willingness to pay to see the Big Five. Journal of Economic and Financial Sciences, Johannesburg, v. 6, n. 3, p. 631-644, 2013.

YAO, R. T. et al. Valuing biodiversity enhancement in New Zealand's planted forests: Socioeconomic and spatial determinants of willingness-to-pay. Ecological Economics, Amstrerdam, v. 98, p. 90-101, Feb. 2014. 
Sérgio Roberto Pinto: Universidade Ceuma, São Luís, MA, Brasil

E-mail: sergiorobertopinto1@hotmail.com

Link para o currículo Lattes: http://lattes.cnpq.br/2965157867019811

Abigail Cardoso Coqueiro: Universidade Ceuma, São Luís, MA, Brasil

E-mail: abigail_cardoso@hotmail.com

Link para o currículo Lattes: http://lattes.cnpq.br/3224683798143730

Rodrigo Burkowski: Universidade Federal de Ouro Preto, Ouro Preto, MG, Brasil

E-mail: burkowski.rodrigo@gmail.com

Link para o currículo Lattes: http://lattes.cnpq.br/0696724444875444

Fabrício Brito Silva: Universidade Ceuma, São Luís, MA, Brasil

E-mail: fabricio.brito@ceuma.br

Link para o currículo Lattes: http://lattes.cnpq.br/3322637911743278

Data de submissão: 25 de março de 2019

Data de recebimento de correções: 24 de junho de 2019

Data do aceite: 24 de junho de 2019

Avaliado anonimamente 